\title{
Pontos de vista Outro(s): polifonia e alteridade
}

Tânia Maris de Azevedo"

\section{Resumo}

A Teoria da Polifonia, desenvolvida por Oswald Ducrot, Jean-Claude Anscombre e Marion Carel, propõe que o sentido de enunciados e discursos de uma língua seja constituído de/por vários pontos de vista, várias "vozes", seja a do locutor, seja as dos enunciadores a que o locutor confere espaço em seu discurso. Este trabalho tem por objetivo lançar à discussão a proposta de ver a polifonia linguística como uma relação de alteridade, tal como a define Platão, constitutiva do sentido dos discursos de uma dada língua, ou seja, ver nas atitudes do locutor em relação a cada enunciador por ele mobilizado uma alteridade, um não-ser, que produz sentido. Vista assim, a polifonia linguística pode ser um recurso didático valioso para a aprendizagem de língua, especialmente no que diz respeito à constituição do sentido, quer no que tange à leitura ou à compreensão de discursos orais, quer no que se refere à produção oral ou escrita.

Palavras-chave: Polifonia linguística. Alteridade. Constituição semântica do discurso.

\section{Algumas ideias}

\author{
[...] l'être doit accepter de cohabiter \\ avec le non-être! \\ ([...] o ser deve aceitar coabitar com o \\ não-ser!)
}

Nestor-Luis Cordero

Pensar discurso é pensar complexidade. Seja em que linha for, em que abordagem, em que disciplina linguística, sob que paradigma epistemológico, reconhecer o discurso como fenômeno complexo parece ser indiscutível. Dar conta dessa complexidade, estudá-la em sua integralidade, investigar-lhe os fatores que a constituem tende a ser o ideal de muitas teorias e de vários pesquisadores. E se digo "ideal" é pelo fato de ser tributária da pesquisa que se pretende científica a delimitação de seu objeto de estudo, o re-

\footnotetext{
Doutora em Letras - Linguística Aplicada pela PUCRS. Professora pesquisadora dos programas de pós-graduação em Letras e em Educação e do curso de Licenciatura em Letras da Universidade de Caxias do Sul,RS. E-mail: tmazeved@ucs.br
}

Data de submissão: set. 2015 - Data de aceite: nov. 2015
http://dx.doi.org/10.5335/rdes.v11i2.5504 
corte de seus problemas de investigação, logo, torna-se verdadeiramente difícil e praticamente inviável a uma única pesquisa analisar a alta complexidade do fenômeno linguístico que é o discurso em toda a sua unidade.

Por isso, falar em polifonia no discurso significa tratar apenas uma parte desse universo de relações e interconexões que o compõem; significa pôr sob a lupa as diferentes "vozes" que povoam o discurso, os diversos seres e não-seres que nele coabitam. Mas entender o sentido do discurso pelos pontos de vista que $o$ locutor põe em cena é uma das vias de estudar essa complexidade, não em sua totalidade, obviamente, mas desde uma perspectiva essencial à própria existência do discurso.

De outro viés, ver a polifonia como uma manifestação da alteridade constitutiva do sentido do discurso parece trazer à tona uma questão há muito discutida, mas nem por isso menos relevante e, menos ainda, resolvida. A questão da alteridade foi detalhadamente examinada por Platão, no diálogo $O$ sofista. ${ }^{1}$ Segundo Oswald Ducrot (2009), a noção platoniana de alteridade foi trazida aos alicerces da Linguística por seu fundador Ferdinand Saussure e, decorrência disso, fundamenta também a Teoria da Argumentação na Língua (ANL), de Ducrot e Marion Carel, que a definem como "uma aplicação do estruturalismo saussuriano à semântica linguística" (CAREL e DUCROT, 2005, p. 11). Tamanha é a importância filosófi- co-científica da noção de alteridade que a fez atravessar milênios e continuar a ser objeto de análises e estudos no seio de várias teorias e de diversas áreas do conhecimento.

Pois bem, o que tenciono neste artigo é propor que a concepção polifônica do sentido, de Oswald Ducrot, seja vista como uma relação de alteridade entre locutor e enunciadores e creio que tal proposta possa vir a ser útil nos contextos da pesquisa, no mínimo, por ser uma possibilidade de explicitação de um fundamento da Teoria da Polifonia, e no contexto do ensino de língua, principalmente, no que diz respeito à compreensão leitora.

No sentido da consecução de tal proposta, começo por retomar brevemente o que é discutido no diálogo platoniano sobre alteridade a fim de pôr à mostra que nuances dessa noção, diferentes daquelas trabalhadas por pensadores, como Aristóteles e Emmanuel Lévinas, podem embasar o que proponho.

$\mathrm{Na}$ sequência, penso abordar a versão da Teoria da Polifonia que pretendo analisar aqui, ou seja, aquela apresentada na obra $O$ dizer e o dito (1987), no capítulo VIII, intitulado Esboço de uma teoria polifônica da enunciação, e nas conferências de Cali, na Colômbia, em 1988. Aliás, é preciso apontar o motivo maior para não trazer à discussão os últimos estudos sobre a polifonia realizados por Carel e Ducrot: o fato é que esses estudos ainda estão em fase de elaboração e poderia ser prematuro transformá-los em objeto de investigação sem que fosse sequer formalizada sua última versão. 
Por último, após desenvolver a proposta de ver na polifonia linguística uma alteridade intrínseca, apresentarei um exemplo do que proponho num discurso e algumas possibilidades de utilização didática da relação polifonia-alteridade no sentido da qualificação da compreensão leitora.

\section{Ser e o não-ser: uma questão de alteridade}

Antes de começar a tratar de um tema tão complexo, um esclarecimento se faz necessário: restringir-me-ei aqui, e por motivos óbvios, a analisar/comentar/ estudar o diálogo $O$ Sofista e, portanto, a questão da alteridade platoniana, desde a perspectiva de sua necessidade para entender os fundamentos saussurianos da linguística e, assim sendo, também os alicerces da Teoria da Polifonia, de Oswald Ducrot, objeto deste artigo. Além disso e dadas as limitações de um texto como este e as minhas no âmbito da filosofia, utilizarei para abordar a referida questão, afora as reflexões de Ducrot no prefácio que faz ao Intervalo semântico, de Carlos Vogt, os comentários de Nestor-Luis Cordero, feitos na introdução da tradução que este filósofo faz do diálogo $O$ Sofista, do grego para o francês.

Tomando em conta tal elucidação, nada mais justo do que começar a abordagem do tema pelas ideias do próprio Ducrot acerca da alteridade em Platão como base da linguística saussuriana. Então, de acordo com Ducrot (2009, p. 10), Platão apresenta uma "teoria da alteridade" no diálogo O Sofista da qual a linguística moderna, desde Saussure, se vale como fundamento.

Nesse diálogo, Platão elenca e descreve os "gêneros primeiros" ou as categorias fundamentais da realidade: o Movimento, o Repouso, o Mesmo e o Ser. E acrescenta a esses quatro gêneros o Não-ser, ou, como diz Ducrot, o Outro, que, no diálogo, aparece com uma natureza totalmente diferente dos demais, visto que integra a essência dos outros quatro gêneros, transformando-se no "fundamento de todos os outros" (2009, p. 10).

Indo à fonte, no que diz respeito ao Não-ser, temos no diálogo:

$\mathrm{E}$ diremos que permeia a todos, uma vez que cada um deles é diferente dos demais, não por razão de sua própria natureza, mas porque partilha da forma ou ideia do diferente (PLATÃO, 255e, grifos do autor).

Portanto, é pela diferença que se define a essência do ser, é pela própria oposição ao Outro, ao Não-ser que se delineia e se constitui a natureza de cada uma das categorias primeiras: por exemplo, o Movimento se define por seu não-ser que é o Repouso e, vice-versa, o Repouso se define por seu não-ser, o Movimento. Assim as categorias primeiras definem-se negativamente, umas em relação às outras.

Ora, o que é a diferença platoniana senão a relação, a oposição, o valor em Saussure? Eis um dos motivos de a alteridade platoniana ser tida por Ducrot como um (ou, mais ousadamente, o) alicerce de toda a linguística do mestre genebrino. Conforme Ducrot, Saussure aplica: 
[...] às palavras da língua o que Platão disse sobre as Ideias. A oposição, para Saussure, é constitutiva do signo da mesma forma que a alteridade é, para Platão, constitutiva das ideias. O valor de uma palavra - ou seja, sua realidade linguística - é o que a opõe às outras. Indo mais longe, é a de se opor às outras. Seu ser é ser outro (2009, p. 10-11).

Obviamente, todos lembram de que Saussure, ao tratar da noção de valor, disse que um signo é o que os outros não são. Ora, aí está mais uma vez clara a alteridade que constitui o signo linguístico. A característica maior e mais exata do signo é a de não-ser nenhum outro signo no interior do sistema linguístico, sistema que, aliás, só é sistema por ser considerado o lugar linguístico da alteridade, da oposição, da diferença e, portanto, da negatividade; a língua, para Saussure, se define pela alteridade que rege e configura o sistema de signos que ela é.

Voltando a Platão, consoante Cordero:

O ser, que escapa assim da 'coisificação', torna-se uma verdadeira potência (dynamis) que cria as realidades a se misturar, e é essa beleza de mistura que as coisas são. É nessa possibilidade de comunicação com outras realidades que cada coisa chega a constituir sua essência: toda coisa é, com efeito, o mesmo que ela mesma, e diferente das outras; aí estão seus limites, ou seja, sua essência. Identidade e diferença são assim dois princípios supremos - tornados possíveis pela comunicação recíproca - que definem cada coisa. E cada coisa, do fato de participar (ainda um tipo de comunicação) do ser, torna-se uma ousía [essência, substância] da parte inteira (1993, p. 25-26, grifos do autor).

Para Cordero, em Platão, a negação do não-ser não é nada mais do que a diferença e, então, afirmar que uma coisa não é equivale a dizer que essa coisa é apenas diferente de outra. É assim que a alteridade, o Outro, o não-ser constitui o ser; é da natureza do ser a sua diferença com relação ao Outro. Ou seja,

[...] a negação não significa "contradição" (ou oposição); ela significa "diferença”. Uma coisa (um fato, um estado de coisas) negada é uma realidade diferente daquela que se tem negado. Entretanto, ela é tão real quanto sua parceira "positiva” (1993, p. 56, grifos do autor).

Essa alteridade constitutiva defendida por Platão parece ter no seu cerne o conceito de relação, isto é, o Movimento em relação ao Repouso, o Mesmo em relação ao Ser e o Não-ser em relação a todas as demais categorias, o "gênero dos gêneros”, diria Ducrot (2009, p. 10). Ora, para Saussure e para Ducrot, esse mesmo conceito de relação embasa, fundamenta, costura, configura e dá o tom às suas teorias. Todos os construtos teóricos de um e de outro são cunhados nos moldes da relação, da diferença, da negatividade, como em Saussure, língua / fala, valor, associação / combinação, significante/significado, ou em Ducrot, frase / enunciado, texto/discurso, significação/sentido. ${ }^{2}$

Da relação recíproca dos gêneros, Platão tirou como consequência que o não-ser, em relação a cada Forma, é o que ela não é. [...] Mas, em todo o caso, o não-ser foi definido em relação a qualquer coisa. Trata-se francamente de um não-ser, mas relativo: não-ser é não-ser X. [...] Desde que se suprima $\mathrm{X}$, o não-ser desaparece.

Não há, apesar do que disse Platão, [...] um não-ser em si (CORDERO, 1993, p. 57).

No livro Escritos de linguística geral, que reúne alguns dos manuscritos de Saussure, quando ele discorre sobre a lingua, afirma claramente: 
Considerada de qualquer ponto de vista que pretenda ter em conta sua essência, a língua consiste, não em um sistema de valores absolutos ou positivos, mas em um sistema de valores relativos e negativos, que não tem existência, a não ser como efeito de sua oposição (SAUSSURE, 2004, p. 74).

É de se notar que a oposição é aqui assimilada à negatividade, isto é, ao não-ser.

Considerando as palavras de Cordero e as de Saussure citadas acima, é possível ver a "coincidência" do adjetivo relativo, no primeiro referindo-se ao não-ser e, no segundo, ao sistema de valores. Por esse adjetivo - que não por acaso corresponde ao conceito basilar da linguística saussuriana, o conceito de relação - parece ficar claro que assim como não há o não-ser em si, não há também a língua em si ou o valor linguístico em si, pois a língua em Saussure é pura relação e negatividade.

Já que pretendo tratar da polifonia como forma de alteridade na próxima seção e como não posso me alongar nas questões da alteridade como vista pelo filósofo grego, dadas as circunscrições de um artigo como este, farei uma breve citação de Cordero quando ele aborda o que chama de teoria platoniana da enunciação:

A teoria platoniana da enunciação (ou do 'discurso') é uma aplicação ao domínio da linguagem de sua nova concepção do ser como potência de comunicação ou de ligação, de relação entre as Formas, e do não-ser como alteridade (1993, p. 62).

Então, é possível conjecturar que teorias linguísticas como a de Saussure e a de Ducrot, fundadas que são no princípio da relação, possam ser tidas como uma aplicação da ideia platoniana de "ser como potência de comunicação ou de ligação", por um lado, e, por outro, da concepção platoniana de "não-ser como alteridade", pois é o Outro que possibilita a relação constitutiva da natureza do ser linguístico, do sistema de signos e dos valores semânticos, baluartes dessas teorias linguísticas.

A partir daqui passo, como já mencionei, a discutir a Teoria da Polifonia, de Oswald Ducrot, como fundada em uma relação de alteridade de caráter platoniano para, na sequência, discorrer sobre as consequências dessa visão da polifonia no ensino da compreensão leitora.

\section{Vozes outras que se manifestam}

Em 1988, Oswald Ducrot realiza em Cali, na Colômbia, uma série de conferências que foram reunidas no livro intitulado Polifonia y argumentación: conferencias del seminário Teoría de la Argumentación y Análisis del Discurso, publicado em 1990. O primeiro capítulo desse livro, La polifonia en lingüística, é dedicado a expor a concepção polifônica do sentido, elaborada por Ducrot já em 1980, na obra Les mots du discours, e reformulada em 1987, na obra $O$ dizer e o dito. Como já mencionado e justificado na primeira seção deste artigo, limitar-me-ei a abordar a Teoria da Polifonia que é divulgada por Ducrot na obra de 1987 e no evento supracitado.

Ducrot (1990) começa seu texto dizendo de sua tentativa de adaptar a noção bakhtiniana de polifonia à análise 
propriamente linguística de enunciados, mostrando que o autor nunca se expressa diretamente, mas põe em cena em um mesmo enunciado um dado número de personagens. Portanto, o sentido dos enunciados de uma dada língua "nace de la confrontación de esos diferentes sujetos: el sentido del enunciado no es más que el resultado de las diferentes vozes que allí aparecen.” (1990, p. 16). E nesse dizer do semanticista vemos o primeiro indício da alteridade que constitui sua Teoria quando fala da "confrontação" de "diferentes sujeitos", ou seja, é na relação ser/não-ser, eu/outro que "nasce" o sentido de um enunciado.

Em $O$ dizer e o dito, Ducrot afirma que o enunciado contém em si uma "qualificação da enunciação", o que consiste no sentido do enunciado. Assim, o objeto da semântica linguística é o de explicar o que, conforme o enunciado, é "feito pela fala". Para tanto, "é necessário descrever sistematicamente as imagens da enunciação que são veiculadas pelo enunciado" (1987, p. 163-164).

Antes, porém, de apresentar aqui a concepção polifônica do sentido, alguns esclarecimentos conceituais e terminológicos se impõem. O próprio Ducrot faz isso na obra de 1987, trazendo novamente à discussão distinções conceituais já apresentadas, no mínimo, em 1984, na enciclopédia Einaudi, no verbete Enunciação. Trata-se das diferenciações, estabelecidas metodologicamente no contexto da Teoria da Argumentação na Língua, entre frase/enunciado, texto/discurso, significação/sentido e enunciação.
Convido o leitor a percorrer brevemente comigo esses conceitos começando pelo par frase / enunciado. Por frase, Ducrot entende o material linguístico, não observável, subjacente a qualquer enunciado e que se mantém igual independentemente de sua realização linguística, feita pelo enunciado, esse, sim, um observável concreto da frase atualizada, ${ }^{3}$ já que pode ser ouvido ou lido, pode ser gravado ou grafado. Mas frase e enunciado são entidades de nível simples, ao passo que texto e discurso, seus correspondentes respectivos, são entidades de nível complexo, uma vez que o texto é uma organização abstrata, teoricamente criada pela interconexão de várias frases, e o discurso é igualmente uma organização, só que concreta, pois é concebido como a realização linguística do texto, ou seja, uma unidade de sentido constituída pela interconexão de enunciados de uma determinada língua.

Por falar em sentido, em muitos de seus textos, Ducrot (1980, 1984, 1987, 1990 entre outros) diz concebê-lo arbitrariamente como o valor semântico das entidades concretas, a caracterização semântica do enunciado e do discurso, em oposição à significação, que corresponde ao valor semântico das entidades abstratas, descrição semântica da frase e do texto. Apresenta-se no Quadro 1 as diferenças apontadas por Ducrot (1987, p. 170-171) entre sentido e significação. 
Quadro 1 - Diferenças entre sentido e significação

\begin{tabular}{|c|c|c|}
\hline Diferença & Sentido & Significação \\
\hline Metodológica & $\begin{array}{l}\text { - pertence ao domínio do observável, ao } \\
\text { domínio dos fatos } \\
\text { - construído por meio de hipóteses expli- } \\
\text { cativas }\end{array}$ & $\begin{array}{l}\text {-pertence ao âmbito da abstração, } \\
\text { da teorização } \\
\text { - resultado das hipóteses explicati- } \\
\text { vas, objeto teórico }\end{array}$ \\
\hline de natureza & $\begin{array}{l}\text { - construção realizada considerando a si- } \\
\text { tuação de discurso, a partir das instruções } \\
\text { "especificadas" na significação } \\
\text { - descrição, representação da enunciação }\end{array}$ & $\begin{array}{l}\text { - conjunto de instruções para a in- } \\
\text { terpretação dos enunciados/discur- } \\
\text { sos produzidos }\end{array}$ \\
\hline
\end{tabular}

Fonte: elaborado pelo autor.

Chegando ao último conceito basilar desse grande parêntese aberto aqui, Ducrot (1987, p. 168-169) discute as três acepções de enunciação, como: a) atividade psico-fisiológica pressuposta pelo processo de produção de um enunciado, cujo estudo não pertence à semântica linguística; b) "produto da atividade do sujeito falante", ou seja, um segmento de discurso, um enunciado; c) "o acontecimento constituído pelo aparecimento de um enunciado", "o fato de que um enunciado [como acontecimento histórico, logo datado e situado espacialmente] aparece", isto é, para uma teoria semântico-linguística, um conceito desprovido, desde o início, da noção de sujeito falante, e que, justamente por isso, tem lugar na teoria ducrotiana.

Voltando ao assunto, concepção polifônica do sentido vai se opor, então, ao pressuposto da unicidade do sujeito falante - prevalente na linguística da época, segundo o próprio Ducrot (1990) -, ou seja, à ideia de que cada enunciado de uma língua seria produzido e atualizado por um único sujeito. Para tal oposição, Ducrot cria o que ele chama de teoria polifônica da enunciação, que parte da tese de que "en un mismo enunciado hay presentes varios sujetos con status linguísticos diferentes" (1990, p. 16). Para ele, a ideia de sujeito falante alude a três funções discursivas diferentes: a de sujeito empírico, a de locutor e a de enunciador.

A função de sujeito empírico (SE), no âmbito da teoria da polifonia (TP),${ }^{4}$ corresponde ao produtor efetivo do enunciado, e, conforme Ducrot, determinar quem é o autor efetivo de um enunciado não é um problema da ciência linguística:

El linguista y en particular el linguista semanticista debe preocuparse por el sentido del enunciado, es decir debe describir lo que dice el enunciado, lo que éste aporta. De manera que lo que interessa es lo que está en el enunciado y no las condiciones externas de su producción. El problema (importante) de la determinación del SE es más bien preocupación de los sociolingüistas o los sicolingüistas, que se formulan preguntas como ¿por qué el señor $\mathrm{X}$ dijo lo que dijo? Lo que a mí me interessa es sencillamente lo que dijo el señor X (1990, p. 17, grifo do autor). 
Aqui é possível perceber a filiação saussuriana de Ducrot, da qual eu falava no início deste artigo: o que cabe ao linguista como objeto de estudo é o que diz o enunciado, o estritamente linguístico - com base no princípio saussuriano da imanência -, e não o contexto extralinguístico em que o enunciado é realizado, ou mesmo as razões sociais, psicológicas ou de qualquer outra ordem que levam alguém a dizer algo. E não há nessa forma de pensar nenhum desprezo ao que ocorre nas situações discursivas, extralinguísticas de um enunciado, crítica recorrente aos trabalhos de Saussure e Ducrot, o que existe, sim, é um recorte metodológico, procedimento pertinente e necessário para garantir a cientificidade de suas pesquisas.

Já que são as funções discursivas locutor e enunciador o que deve ser analisado e explicado pela concepção polifônica do sentido, vamos a elas. Por locutor, Ducrot (1990) entende o responsável pela enunciação no interior do próprio enunciado, "um ser que é, no próprio sentido do enunciado, apresentado como seu responsável" (DUCROT 1987, p. 182), em última análise, a quem se atribui a responsabilidade pelo sentido do enunciado produzido. O locutor L é marcado no enunciado pelos índices de primeira pessoa, pronomes, como eu, me, mim, por exemplo, e por indicadores do tempo e espaço da enunciação, como agora, hoje, aqui. Para o semanticista, "el locutor puede ser totalmente dife- rente del SE, a menudo es un personage ficticio a quien el enunciado atribuye la responsabilidade de su enunciación" (1990, p. 18). Um exemplo claro dessa situação é um enunciado do tipo Como eu sou inteligente! diante de alguém que cometeu um grande engano, pois o $e u$ manifesto no enunciado não designa quem o proferiu, mas, pelo contrário, marca o interlocutor que cometeu o engano, como uma espécie de repreensão do SE que atualiza esse enunciado. Nesse sentido, o eu do enunciado proferido refere-se à pessoa a quem o $\mathrm{SE}$ se dirige, portanto, um locutor totalmente diferente do próprio SE que realizou o enunciado.

Consoante Ducrot (1990, p. 18), essa distinção locutor / sujeito empírico possibilita-lhe dar "voz" a seres que são incapazes de falar. Para explicar esse fenômeno semântico, Ducrot usa um exemplo semelhante ao que apresento aqui: quantas vezes vemos em folhagens ou em árvores placas dizendo Por favor, não jogue lixo em mim!. Quem, nesse enunciado, é designado pelo mim? Quem é o SE desse enunciado? Com certeza, o pronome mim refere-se à folhagem ou à árvore, que, sem dúvida, não pode ser um SE e que, entretanto, é apresentado como o locutor do enunciado.

Ainda, em se tratando da diferença locutor/sujeito empírico, Ducrot menciona o caso dos provérbios que são desprovidos da função locutor. Diz ele: 
Cuando hablamos con proverbios, es precisamente para favorecer la interpretación según la cual el responsable de lo que décimos sería completamente ajeno a la situación de discurso en la que nos encontramos. Supongamos que por querer reprochar a alguien el hecho de incitar a otro al desorden, le diga "Quien siembra ventos recoge tempestades". Al utilizar este enunciado impersonal busco que mi palavra no aparezca como proveniente de mí, individuo particular, sino que me gustaría que apareciera como salida de una sabiduría situada más allá de cualquier subjetividade individual (1990, p. 19).

Creio que esses exemplos são suficientes para não só refutar a tese da unicidade do sujeito falante como também para demonstrar a diferença existente no contexto da Teoria da Polifonia entre as funções de locutor e sujeito empírico.

A terceira função discursiva que Ducrot (1990) refere é a de enunciador. O semanticista parte da ideia de que todo enunciado de uma língua apresenta um determinado número de pontos de vista relativos às situações das quais o enunciado fala.

Em $O$ dizer e o dito, Ducrot define os enunciadores como:

[...] estes seres que são considerados como se expressando através da enunciação, sem que para tanto se lhe atribuam palavras precisas; se eles 'falam' é somente no sentido em que a enunciação é vista como expressando seu ponto de vista, sua posição, sua atitude, mas não, no sentido material do termo, suas palavras (1987, p. 192).

Às origens desses pontos de vista, Ducrot (1990, p. 20) chama enunciadores, ressaltando que não são pessoas, mas pontos de perspectiva abstratos com alguns dos quais o próprio locutor pode ser assimilado; no mais das vezes, contudo, o locutor apresenta esses pontos de vista distanciando-se deles, recusando-os ou simplesmente aceitando-os, mas não os assumindo. De acordo com Ducrot, o locutor e os enunciadores são seres do discurso, pertencentes "ao sentido do enunciado", e resultantes "desta descrição que o enunciado dá de sua enunciação" (1987, p. 195).

De acordo com a concepção do semanticista parisiense, o locutor pode adotar três atitudes em relação a cada enunciador mobilizado para a realização de um enunciado. A primeira delas consiste em aceitar o ponto de vista de um enunciador, como no caso da pressuposição. Num enunciado como João parou de atormentar Maria, o locutor aceita o pressuposto de que João atormentava Maria e não a atormenta mais.

A segunda atitude do locutor consiste em recusar o ponto de vista de um enunciador, como ocorre num discurso como João comprou e pagou o produto, mas não o recebeu, no qual o locutor recusa o enunciador que diz que, se João comprou e pagou, deveria ter recebido o produto, caso que explica o uso do articulador mas, pois a oposição se faz entre o enunciador que afirma o recebimento do produto e o que o nega.

A terceira atitude do locutor em relação a um enunciador corresponde a de assumir seu ponto de vista, como no exemplo anterior em que o locutor assume o enunciador que nega o recebimento do produto.

Partindo dessas duas funções, a de locutor e a de enunciador, descrever o sen- 
tido de um enunciado consiste, de acordo com Ducrot, entre outras coisas, em:

[...] responder a diversas preguntas: ¿el enunciado contiene la función locutor?, ¿a quién se le atribuye esta función?, ¿a quién se assimila el locutor?, icaules son los diferentes puntos de vista expressados, es decir cuáles son las diferentes funciones de enunciador presentes en el enunciado?, ¿a quién se atribuyen eventualmente estas funciones? (1990, p. 20).

Um dos exemplos que Ducrot (1987) dá de fenômeno linguístico essencialmente polifônico é o da negação. $O$ enunciado negativo traz em seu sentido claramente dois enunciadores, um positivo, $\mathrm{E}_{1}$, e outro que se manifesta como oposto a este, o negativo, $\mathrm{E}_{2}$.

Analisemos polifonicamente, a título de exemplo, o enunciado (1) abaixo.

\section{(1) Lucas não respondeu à pergunta}

Em (1) aparecem nitidamente dois enunciadores: $\mathrm{E}_{1}$ que afirma a resposta de Lucas à pergunta e $\mathrm{E}_{2}$ que nega essa resposta. Assim teríamos:

$\mathrm{E}_{1}$ : Lucas respondeu à pergunta

$$
\mathrm{E}_{2} \text { : Lucas não respondeu à pergunta }
$$

E quanto às atitudes do locutor $\mathrm{L}$ em relação a cada enunciador mobilizado, direi que L aceita $\mathrm{E}_{1}$, mas assume $\mathrm{E}_{2}$.

Caso (1) fosse sucedido pelo enunciado (2):

(1) será reprovado, teríamos uma sequência como

Lucas não respondeu à pergunta, portanto será reprovado, na qual o enunciador $\mathrm{E}_{1}$, o que afirma a resposta de Lucas, apareceria claramente como a condição da aprovação de Lucas e $\mathrm{E}_{2}$, que nega a resposta de Lucas, como a causa de sua reprovação.

Ducrot (1990, p. 25) refere-se ao enunciado negativo como um "diálogo cristalizado":

Diré pues que el enunciado negativo es una espécie de pequena obra de teatro con dos personajes a quienes llamo enunciadores. El enunciado presenta, a pesar de su apariencia monológica, un diálogo cristalizado. $\mathrm{He}$ dicho que el enunciador $\mathrm{E}_{2}$ generalmente se asimila al locutor, lo que no ocurre cone el enunciador $\mathrm{E}_{1}$, que puede ser asimilado a cualquiera, menos al locutor (1990, p. 25).

Creio que o leitor possa ter tido, no mínimo, uma noção dos principais conceitos e pressupostos da Teoria $d a$ Polifonia, por isso passo agora a tentar demonstrar como é possível ver nela a alteridade que a constitui.

A proposta que trago à discussão neste artigo trata de conceber a relação locutor / enunciador como uma relação de alteridade, de ser e não-ser.

A própria menção a "diálogo cristalizado”, feita na citação acima, já é uma marca dessa alteridade constitutiva do sentido, pois um diálogo ocorre sempre entre um $e u$ e um $t u$, no caso em questão, entre o locutor de um enunciado negativo e os enunciadores, positivo e negativo, a que o locutor dá voz no enunciado produzido.

Ducrot propõe a seguinte paráfrase do que diz Platão: 
Se o Movimento é diferente do Repouso, não é porque o Movimento possui em si mesmo tal ou qual característica positiva que podemos perceber quando o consideramos isoladamente, característica que se revelaria diferente daquelas, igualmente positivas, que possui o Repouso. Ao contrário, a diferença entre o Movimento e o Repouso é constitutiva dessas mesmas noções. O Movimento é aquilo que ele é, pelo fato de que ele é outro, diferente do Repouso, do Mesmo... etc. $(2009$, p. 10$)$.

Parafraseando, agora, Ducrot, direi que, se o Locutor é diferente do Enunciador, não é pelo motivo de ele ter em si mesmo uma ou outra característica positiva que possa ser percebida quando o concebemos isoladamente, característica que se mostraria diferente daquelas, igualmente positivas, que o Enunciador possui. Pelo contrário, a diferença entre Locutor e Enunciador é constitutiva dessas duas noções. O Locutor é aquilo que é justamente por ser outro, diferente do Enunciador (2009, p. 10-11).

Assim como, para Saussure, a oposição é constitutiva do signo, a alteridade é constitutiva da polifonia linguística. A concepção de Locutor é o que o opõe a Enunciador, é a de se opor à concepção de Enunciador. "Seu ser é ser outro" (DUCROT, 2009, p. 11).

Nesse sentido, quando o locutor põe em cena no interior do próprio enunciado pontos de vistas diferentes, ele está, na verdade, atualizando enunciadores, que, por sua diferença, o constituem e, por conseguinte, essa diferença, essa oposição locutor/enunciador constitui o sentido do enunciado produzido.
Consoante Ducrot, linguistas cujas pesquisas derivaram dos pressupostos de Émile Benveniste, atribuem à linguagem uma função que se satisfaz "com a pura alteridade", pois para eles a:

[...] língua é, antes de mais nada, o lugar da intersubjetividade, o lugar onde os indivíduos se confrontam, o lugar onde encontro outrem. Ora, outrem, ou não é nada, ou é este outro constitutivo de que fala Platão, este outro que me constitui a mim mesmo, porque é somente através dele que posso me ver e é através do seu reconhecimento que posso me conhecer. Pensar que sou este ou aquele é sempre imaginar alguém que me vê como este ou como aquele, e cujo olhar me constitui. Mas se outrem tem esta função constitutiva do Outro platoniano, e se a língua é, antes de mais nada, o terreno onde afronto outrem, não nos surpreenderemos com o fato de a realidade linguística ser, como viu Saussure, fundamentalmente opositiva. Pois uma entidade linguística (um enunciado, por exemplo) não poderá definir-se independentemente de seu emprego num diálogo. Dar sua significação será indicar qual ato está sendo realizado quando o utilizamos para nos dirigir a um interlocutor. E o ato linguístico fundamental será o de impor ao interlocutor tal ou qual tipo de resposta, impedindo simultaneamente tal ou qual outra (2009, p. 11).

Ora, Ducrot é um desses pesquisadores que, embora circunscreva seus estudos ao contexto linguístico, elabora todos os seus construtos teóricos à luz da oposição, logo da alteridade. Basta voltarmos ao início desta seção para ver essa oposição constitutiva de todos os conceitos ali examinados: frase / enunciado, texto / discurso, significação/sentido. Nenhum desses conceitos tem existência e caracterização em si mesmo, mas sempre por oposição ao(s) outro(s): frase não é senão 
a abstração do enunciado, ao passo que enunciado é visto como a concretização da frase; texto é a organização abstraída do discurso, e discurso é a realização, portanto concretização, do texto; significação é nada mais do que o conjunto de instruções, logo abstrações do nível da langue saussuriana, que possibilita a produção do sentido, que, por sua vez, nada mais é do que a atualização, portanto o correspondente à parole saussuriana, de tais instruções, ou seja, da significação.

No escopo da concepção polifônica do sentido, não me parece ser diferente, pois Ducrot opõe as funções de locutor e de enunciador, assim como as atitudes do locutor em relação aos enunciadores que atualiza no sentido de um enunciado. Aliás, o sentido do enunciado, pela Teoria da Polifonia, é o resultado do confronto dos pontos de vista realizados pelo locutor mais o confronto das atitudes do locutor em relação a cada um desses pontos de vista.

O fato de o locutor escolher no sistema linguístico que enunciadores mobilizar para a construção do sentido de um enunciado já é um indício da alteridade que integra essa relação locutor/enunciador, pois tais escolhas se dão em função da (re)construção do sentido do enunciado produzido pelo interlocutor, objetivo primeiro de qualquer enunciação.

Como eu mesma dizia acerca da polifonia linguística,

reconstruir o sentido de um enunciado, conforme essa concepção, seria, em primeiro lugar, localizar o locutor e os enunciadores por ele postos em cena e, numa segunda etapa, verificar qual é a atitude do locutor em relação a cada um dos enunciadores que atualiza no enunciado (AZEVEDO, 2006, p. 91).

Talvez, essa última ideia fique mais clara se visualizada na Figura 1.

Figura 1 - Constituição polifônica do sentido

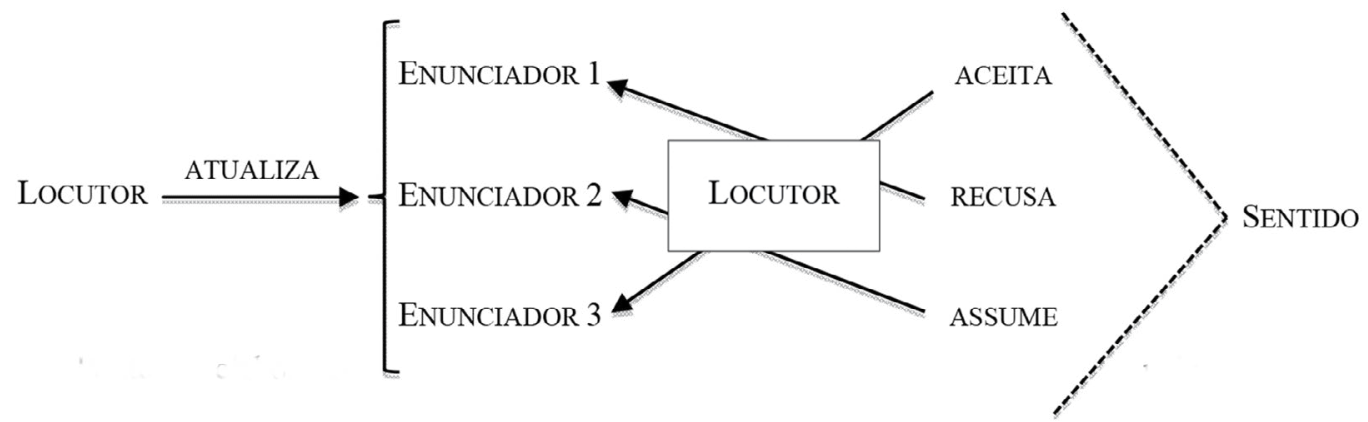

Fonte: elaborado pelo autor.

Ora, se é assim, torna-se possível ver na Teoria da Polifonia duas formas de alteridade que, por uma oposição entre elas, produzem uma terceira relação de alteridade na constituição do sentido.
Explico: a) já coloquei aqui minha proposta de uma alteridade constitutiva dos conceitos de locutor (L) enunciador (E), primeira forma de alteridade; b) a relação entre as atitudes que o locutor 
pode adotar frente a cada enunciador também pode ser vista como outra forma de manifestação da alteridade, uma vez que aceitar se define por oposição a recusar e a assumir, a atitude de recusar também se constitui pela oposição às atitudes de aceitar e assumir, e igualmente a oposição com as atitudes de aceitar e recusar é definidora da atitude de assumir, segunda forma de alteridade; c) o sentido de um enunciado constrói-se pelo confronto não só dos enunciadores com o locutor, mas inclusive das atitudes de $\mathrm{L}$ em relação a cada $\mathrm{E}$, terceira forma de alteridade. Quiçá, a Figura 2 torne mais visível essa explicação.

Figura 2 - Alteridade constitutiva do sentido polifônico

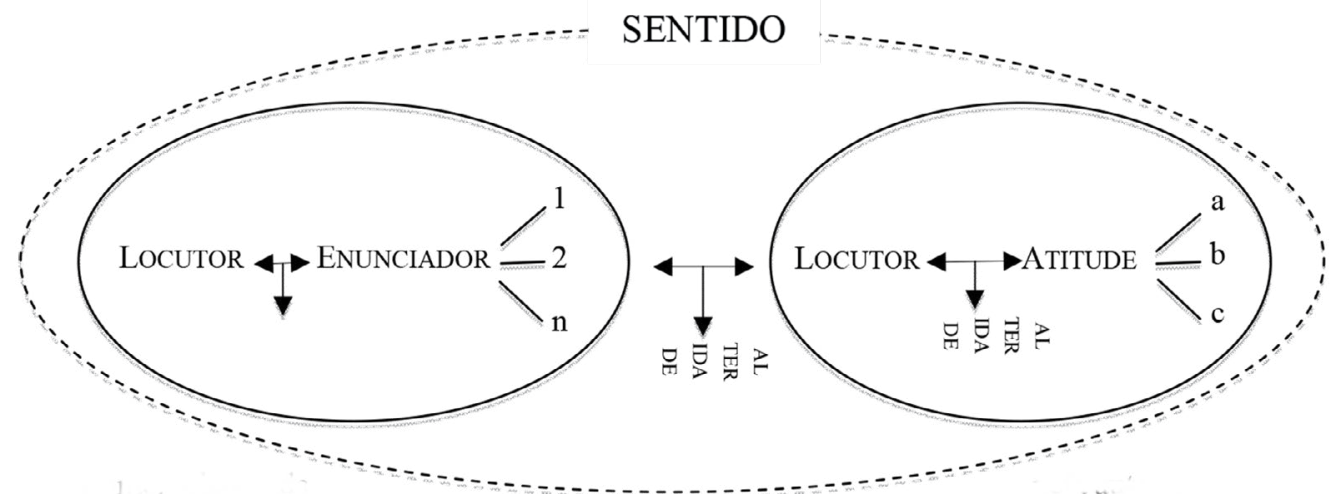

Fonte: elaborada pela autora.

Todo esse emaranhado de relações de oposição é fundamental à constituição e, portanto, à descrição do sentido de enunciados e discursos de uma língua, logo, a relação de alteridade é essencial à concepção polifônica do sentido, ao menos, como Ducrot a elaborou. Então, não parece ser possível compreender efetivamente um enunciado ou um discurso de uma determinada língua sem que sejam reconhecidas essas três formas de alteridade.

Importante dizer que "ser reconhecida" não tem o sentido, em hipótese alguma, de identificar a metalinguagem ou os construtos teóricos da polifonia linguística, pois essa não é tarefa do usuário de uma língua, mas dos linguistas semanticistas que procuram descrevê-la e explicá-la.

\section{Alteridade polifônica e compreensão leitora}

Agora, convido o persistente leitor a seguir comigo pela análise polifônica de um discurso, extraído de um livro didático, de Marco Antonio Villa, destinado ao ensino de História para o quarto ano (quinta série) do ensino fundamental. Esse discurso compôs o corpus da pesquisa Argumentação a serviço da formação de conceitos, coordenada por mim e 
concluída em 2012. Tal análise será aqui apresentada com o intuito de demonstrar como a alteridade constitutiva da polifonia linguística pode colaborar para o desenvolvimento da compreensão leitora.

Torna-se pertinente ressaltar que não farei aqui, até pelos limites próprios deste artigo, a descrição semântica dos intensificadores e modificadores que compõem o discurso, restringir-me-ei a descrever os enunciadores mobilizados pelo locutor, bem como as atitudes deste em relação a cada um daqueles, pois é aí que reside a alteridade objeto da proposta que trago à discussão e que pode contribuir com a compreensão do referido discurso, que explica o objeto de estudo da arqueologia e a importância dos achados arqueológicos para o estudo da História.

Consideremos, então, o discurso abaixo.

As escavações arqueológicas são uma forma de recuperar objetos, escritos e até cidades inteiras que, ao longo do tempo, foram cobertas pela terra. A Arqueologia é muito importante para conhecermos a história de povos que viveram há milhares de anos e não deixaram escritos - como os que habitavam as cavernas, na Pré-História. Por meio dos vestígios deixados - pontas de flechas, vasos de cerâmica, restos de fogueira, desenhos nas paredes das cavernas, urnas funerárias, etc. -, é possível entender como viviam esses povos (VILLA, 2002, p. 18).
Seja o enunciado (1):

(1) As escavações arqueológicas são uma forma de recuperar objetos, escritos e até cidades inteiras.

Para a compreensão do sentido de (1), é necessário ao leitor, primeiramente, identificar os enunciadores E mobilizados pelo locutor L, a saber:

$\mathrm{E}_{1}$ : Escavações arqueológicas são um meio de recuperar objetos, escritos $e$ até cidades inteiras; $\mathrm{e}$

$\mathrm{E}_{2}$ : Há outras formas de recuperar objetos, escritos e cidades.

No que diz respeito às atitudes de L para cada enunciador, direi que $\mathrm{L}$ aceita $\mathrm{E}_{2}$ e assume $\mathrm{E}_{1}$. Dessa relação de alteridade de L com o enunciador que assume, constitui-se o sentido de (1) que, por paráfrase, poderia ser expresso por:

(1') Escavações arqueológicas, portanto recuperação de objetos, escritos e cidades inteiras.

Esse é o sentido a ser compreendido pelo leitor do discurso em questão e, ao menos posso cogitar, que, tendo explicitados os enunciadores e as atitudes de $L$ em relação a cada um deles, esse sentido fica muito mais acessível à compreensão. ${ }^{5}$

A partir daqui, por precisar respeitar as limitações deste artigo, passo a apresentar somente a análise polifônica dos demais enunciados do discurso a ser descrito. 
Passemos, então, ao enunciado (2)

(2) cidades inteiras, ao longo do tempo, foram cobertas pela terra.

Em (2), L atualiza os seguintes enunciadores:

$\mathrm{E}_{1}$ : cidades inteiras foram paulatinamente cobertas pela terra; e

$\mathrm{E}_{2}$ : cidades foram parcial e paulatinamente cobertas pela terra.

Quanto às atitudes de $\mathrm{L}$, temos que aceita $\mathrm{E}_{2}$ e assume $\mathrm{E}_{1}$, e o sentido de (2) poderia ser parafraseado por:

(2') cidades, portanto soterramento paulatino.

Eis, agora, o enunciado (3):

(3) A Arqueologia é muito importante para conhecermos a história de povos.

Em (3), o locutor põe em cena os enunciadores:

$\mathrm{E}_{1}$ : A Arqueologia é importante para o conhecimento da história de povos;

$\mathrm{E}_{2}$ : A Arqueologia é importante;

$\mathrm{E}_{3}$ : A Arqueologia é um meio para o conhecimento da história de povos;

$\mathrm{E}_{4}$ : Povos têm história;

$\mathrm{E}_{5}$ : É importante conhecer a história de povos; $\mathrm{e}$

$\mathrm{E}_{6}$ : A Arqueologia tem como objeto de estudo a história de povos.

O locutor L, em (3), aceita $\mathrm{E}_{2}, \mathrm{E}_{3}, \mathrm{E}_{4}$, $\mathrm{E}_{5}$ e $\mathrm{E}_{6}$, assumindo $\mathrm{E}_{1}$. $\mathrm{O}$ sentido de (3) pode ser parafraseado por
(3') Arqueologia, portanto conhecimento da história de povos.

Vamos ao quarto enunciado do discurso:

(4) povos viveram há milhares de anos e não deixaram escritos - como os que habitavam as cavernas, na Pré-História.

Para a constituição do sentido do enunciado (4), L mobiliza os enunciadores:

$\mathrm{E}_{1}$ : Vários povos viveram há milhares de anos;

$\mathrm{E}_{2}$ : Vários povos não deixaram escritos;

$\mathrm{E}_{3}$ : Vários povos deixaram escritos;

$\mathrm{E}_{4}$ : Povos que habitavam as cavernas, na Pré-história, não deixaram escritos;

$\mathrm{E}_{5}$ : Povos que habitavam as cavernas, na Pré-história, deixaram escritos; e

$\mathrm{E}_{6}: N a$ Pré-história existiam povos que não habitavam cavernas.

As atitudes de $\mathrm{L}$ face aos enunciadores que mobilizou foram as de aceitar, $\mathrm{E}_{3}$, $\mathrm{E}_{5}$ e $\mathrm{E}_{6}$ e assumir $\mathrm{E}_{1}, \mathrm{E}_{2}$ e $\mathrm{E}_{4}$. Dito isso, o sentido de (4) poderia ser expresso por:

(4') viver há milhares de anos DC neg-escrita.

No enunciado (5),

(5) Por meio dos vestígios deixados - pontas de flechas, vasos de cerâmica, restos de fogueira, desenhos nas paredes das cavernas, urnas funerárias, etc. -, é possível entender como viviam esses povos, 
o locutor L atualiza os seguintes enunciadores:

$\mathrm{E}_{1}$ : Povos deixam vestígios;

$\mathrm{E}_{2}$ : Vestígios são meios para entender o modo de vida dos povos antigos; $\mathrm{e}$

$\mathrm{E}_{3}$ : É possível entender o modo de vida de povos antigos.

Em (5), L aceita $E_{1}$ e $E_{3}$ e assume $\mathrm{E}_{2}$, e, assim, o sentido desse enunciado poderia ser expresso por:

(5') vestígios DC compreensão do modo de vida.

Por essa análise polifônica fica fácil perceber que tanto a atualização pelo locutor dos enunciadores quanto a relação do locutor com os enunciadores por ele realizados, pelas atitudes que adota frente a cada um deles, são relações de oposição e manifestam a alteridade constitutiva defendida por Platão.

\section{À guisa de breve conclusão}

Creio que essa descrição polifônica, mesmo que sucinta, tenha evidenciado todas as relações de oposição locutor/ enunciador que constituem o sentido do discurso analisado. Se o professor, via questionamentos ou atividades com outros formatos, proporcionar aos alunos a explicitação e o reconhecimento dessas relações durante, por exemplo, o processo de leitura de um discurso, há grande possibilidade de que a compreensão leitora dos alunos seja bastante qualificada, pois a compreensão do sentido de um discurso pressupõe, é o que defendo aqui, a identificação e o entendimento dos enunciadores materializados pelo locutor $\mathrm{L}$, das atitudes de $\mathrm{L}$ em relação a cada enunciador consubstanciado e as oposições instituidoras da alteridade polifônica que compõe o sentido do discurso.

Obviamente, essa utilização pedagógica da alteridade polifônica pressupõe, de um lado, o conhecimento, por parte do professor, da Teoria da Argumentação na Língua - e mais especificamente da Teoria da Polifonia que a integra -, bem como da alteridade platoniana, e, de outro, a transformação desse corpo teórico em "ferramenta" para o desenvolvimento e/ou a qualificação, por parte dos alunos, das habilidades que o uso da língua quer oral, quer escrita, seja em termos de produção ou de recepção discursiva - pressupõe. Mas isso é conversa para um outro artigo.

\section{Points de vue Autre(s): polyphonie et altérité}

\section{Résumé}

La Théorie de la Polyphonie, développé par Oswald Ducrot, Jean-Claude Anscombre et Marion Carel, propose que le sens des énoncés et des discours d'une langue soit constitué de/par plusieurs points de vue, plusieurs "voix", soient-elles celles du locuteur, ou bien celles des énonciateurs auxquels le locuteur donne de l'espace dans son discours. Ce travail a pour objectif ouvrir le débat sur la proposition d'envisager la polypho- 
nie linguistique comme une relation de altérité, telle que Platon la définie, constitutive du sens des discours d'une langue donnée, c'est à dire, voir dans les attitudes du locuteur, liées à chaque énonceur par lui mobilisé, une altérité, un non-être, qui produit du sens. Vu ainsi, la polyphonie linguistique peut être une précieuse ressource pédagogique pour l'apprentissage des langues, en particulier en ce qui concerne la constitution du sens, que ce soit en ce qui concerne la lecture ou de compréhension de discours oraux, en tant que se réfêre à la production orale ou écrite.

Mots-clé: Polyphonie linguistique. Altérité. Constitution sémantique du discours.

\section{Notas}

1 Diálogo que, por vezes, aparece traduzido também como Sofista.

2 Esses conceitos serão definidos, no escopo da ANL, mais adiante neste artigo.

3 Atualizada no sentido de posta em cena, de realizada, manifestada linguisticamente.

4 Como é mais conhecida, ao menos no Brasil.

5 Por óbvio, pelo menos por enquanto, creio ser tarefa do professor questionar seus alunos para fazê-los perceber esses enunciadores e as atitudes de L, para que pudessem, por meio dessa percepção, (re)construir o sentido do enunciado lido. Não posso aqui fazer uma efetiva proposta de transposição didática da alteridade polifônica, por isso, lanço a mim mesma (o que já vem sendo feito na pesquisa que ora desenvolvo) e ao leitor mais curioso o desafio de elaborá-la.

\section{Referências}

AZEVEDO, Tânia Maris de. Em busca do sentido do discurso: a semântica argumentativa como uma possibilidade para a descrição do sentido do discurso. Caxias do Sul, RS: Educs, 2006.
CAREL, Marion; DUCROT, Oswald. La semântica argumentativa: una introducción a la teoria de los bloques semânticos. Edición literária a cargo de María Marta García Negroni y Alfredo M. Lescano. 1. ed. Buenos Aires: Colihue, 2005.

CORDERO, Nestor-Luis. Introduction. In PLATON. Le sophiste. Paris: Flammarion, 1993. p. 11-65.

DUCROT, Oswald. Prefácio. In VOGT, Carlos. O intervalo semântico. 2. ed. rev. São Paulo: Ateliê; Campinas: Unicamp, 2009. p. 9-20.

Polifonía y argumentación - conferencias del seminario Teoría de la Argumentación y Análisis del Discurso. Cali: Universidad del Valle, 1990.

Pontes, 1987.

O dizer e o dito. Campinas, SP:

PLATÃO. Diálogos I: teeteto (ou do conhecimento), sofista (ou do ser), Protágoras (ou sofistas). Tradução, textos complementares e notas Edson Bini. Bauru, SP: Edipro, 2007. (Clássicos Edipro).

SAUSSURE, Ferdinand de. Escritos de linguística geral. São Paulo: Cultrix, 2004.

VILLA, Marco Antonio. Caminhos da história. São Paulo: Ática, 2002. 5ª série. p. 18.

. Enunciação. In: Enciclopédia EINAUDI: Linguagem-Enunciação. Lisboa: Imprensa Nacional-Casa da Moeda, 1984. V. 2, Linguagem - Enunciação, p. 368-393.

Les mots du discours. Paris: Minuit, 1980. 